\title{
REIT Performance and Dynamic Portfolio Considerations
}

\author{
Keyu Feng ${ }^{1, a}$, Yan Yan ${ }^{2, b^{*}}$ and Quanbao $\mathrm{Li}^{3, \mathrm{c}}$ \\ ${ }^{1}$ School of Economics and Management, Beijing Jiaotong University, Beijing, China \\ ${ }^{2}$ School of Management, Graduate University of Chinese Academy of Sciences, Beijing, China \\ ${ }^{3}$ School of Economics and Management, Beihang University, Beijing, China \\ afeng.ky.njtu@gmail.com, bquanbaoli@gmail.com, cyanyan@ucas.ac.cn
}

Keywords: REIT; dynamic portfolio; sharpe ratio; DCC-MGARCH; differential model

\begin{abstract}
Real Estate Investment Trusts (REITs) play an important role in portfolio theory. Conventional portfolio theories assume the constant correlation coefficient, but in reality this correlation is dynamic and conditional. Portfolios could be improved by making timely adjustments to reduce losses in the presence of systemic market risk. This empirical analysis used descriptive statistics, Kernel density estimation and two Sharpe Ratios with different benchmarks to analyze the assets considered. The Sharpe Ratio with a risk-free interest rate indicates that Equity REITs are preferable to stock and direct real estate investments, as do the other statistics. We then employed a DCC-MGARCH model to estimate dynamic volatility and correlations. During the financial crisis, the conditional volatility and correlations rise, and hence portfolio risk increases. In addition, the differential model was refined using the Sequential Elimination of Regressors approach to explore the economic determinants of volatility and correlations. This work demonstrates that Equity REITs, and not all types of REITs, are competitive in the long term. The profit distribution exhibits negative skewness and asymmetry. We find that portfolio performance can be improved by adding Equity REITs, and systemic risk can be reduced by accounting for economic conditions.
\end{abstract}

\section{Introduction}

Real Estate Investment Trusts (REITs) were created to create the opportunity to invest in income-producing real estate. REITs offer a long-term competitive performance record, portfolio benefits and inflation protection. REITs are an ideal asset investment allocation option for low correlation and strong profitability in diversified investment portfolios.

When REITs are included in a portfolio, there are three key considerations: expected return, volatility and correlation. Intrinsic correlation exists in the multivariate model, which must be estimated as a complete system. However, in reality, it is insufficient to assume constant parameters. The model must account for time-varying characteristics, including dynamic conditional volatility and dynamic conditional correlation, and their dynamic impacts resulting from macro-economic determinants.

Multivariate GARCH (MGARCH) models often used to handle correlated financial returns. For example, asset pricing depends on the covariance of the assets in a portfolio, and risk management and asset allocation relate, for instance, to finding and updating optimal hedging positions (Silvennoinen \& Svirta, 2009[1]). To date, scholars have applied numerous types of MGARCH models using different specifications. Diagonal VECH-GARCH (Bollerslev et al., 1988[2]) and BEKK-GARCH (Engle and Kroner, 1995) models were the most popular at the end of the 20th century. More recently, dynamic conditional correlation (DCC) MGARCH (Engle, 2002[3]) has become the most common approaches.

Many studies have explored REIT performance. Since Markowitz (1952) proposed the first iteration of portfolio theory, risk and expected return have remained the two core considerations. [4] These concepts are still applied when evaluating the performance of securities. Devaney and Weber (2005) estimated REIT efficiency by constructing a risk/return frontier, in which each REIT produces a desirable output (return) and an undesirable output (risk).[5] The capital asset pricing model (CAPM) was directly developed from Markowitz's model. One of its applications is the Sharpe Ratio, 
named for William Forsyth Sharpe, which is a practical approach for examining the performance of an investment by adjusting for its risk.[6] Sharpe Ratios are often used to rank the performance of portfolios. With the development of financial econometrics, researchers have sought to better understand the law describing the volatility of REITs, which contains dynamic and dependent components. Jirasakuldech et al. (2009) examined the dynamic volatility of Equity REITs in a GARCH context using monthly returns and found that conditional volatility was time-varying, persistent, and predictable, and none of their evidence indicated that Equity REITs exhibited asymmetric volatility in response to negative or positive shocks.[7] $\mathrm{Wu}$ et al. (2010) tested the defensive property of REITs by employing DCC-TGARCH using daily data and reported that REITs were defensive at lower downside betas when the market declined than those when the market remained relatively constant.[8] Considering different data periods leads to different findings on asymmetry. Fei et al. (2010) explored asymmetry in conditional correlation through an AG-DCC GARCH specification using monthly data and found that the asymmetric terms were not statistically significant at the 95\% confidence level.[9] Yang et al. (2012) employed an AG-DCC GARCH using daily data, and their results suggested that asymmetry was widespread and the recent financial crisis generated a significant structural break in the correlations.[10] Dependence concerns regarding REITs are addressed using multiple factor models. Erol and Ileri (2013) investigated the macroeconomic sources of time-varying risk premiums in Turkish REITs within the arbitrage pricing theory framework. Their results provided evidence of time-varying linkages among macroeconomic risks.[11] .Guo and Cai (2013) derive analytical expressions for the optimal portfolio policy and the mean-variance efficient frontier under certain conditions.[12] The abovementioned studies indicate that: (1) REITs generally have good profit/risk ratios; (2) volatility and correlation are time-varying; (3) asymmetry can only be detected using daily data, while it cannot be statistically proven using monthly data; and (4) macroeconomic variables have significant explanatory power with respect to REIT volatility and correlation.

This study makes three contributions to the literature. First, we recalculate statistical performance data on stock, direct real estate and REIT returns using monthly data from Jan. 1987 to Feb. 2014. In contrast to prior studies, we adjust the Sharpe Ratio process using a risk-free benchmark and obtain the novel result that REITs significantly outperform direct real estate assets. Second, we employ a DDC-MGARCH model to examine the volatility and correlation dynamics using monthly logarithmic returns. Third, we estimate regression models of volatility and correlations that include five macroeconomic variables and employ a finite difference model in place of a distributive lagging model for the non-stationary process of economic factors.

This paper proceeds as follows: the data section describes the data used. The empirical section addresses REIT performance, the dynamic volatility and correlations of assets, and their economic determinants. Final section concludes this work and discusses how it differs from previous efforts.

\section{Data}

The empirical analysis conducted in this study utilizes monthly data on stocks, unsecuritized real estate, REITs and five economic factors in the U.S. market. The data retrieved range from Jan. 1987 to Feb. 2014.

S\&P 500 monthly data, calculated at the close of the last trading day in each month, are employed to represent the stock market. The required daily data are exported from Yahoo Finance.

There are several major housing indexes commonly employed in the literature to track the performance of the U.S. housing market. The S\&P/Case-Shiller 10-City Composite Home Price Index, also called CSXR, is used in this study. The key reason is that the analysis conducted below requires the availability of monthly and long-term data. The S\&P/Case-Shiller 20-City Composite Home Price Index, which is far more comprehensive than 10-City index, was not released until Jan. 2000. An attempt to merge the 10-City and 20-City indexes is likely questionable. The National Association of Realtors (NAR) Indexes calculate the median price of houses sold, which creates a significant potential bias. The Office of Federal Housing Oversight (OFHEO) Indexes are quarterly home price 
indicators and exhibit some smoothing because they include appraisal data. The CSXR composite index is obtained from the Federal Reserve Economic Data (FRED) database.

Three types of transformation will be used in the following empirical analyses. For the price index data, $P_{i, t}$, at time $t$, the monthly return $r_{i, t}$ is

$$
r_{i, t}=\frac{P_{i, t}-P_{i, t-1}}{P_{i, t-1}}
$$

where $P_{i, t}$ and $P_{i, t-1}$ are the closing prices of asset $i$ at times $t$ and $t-1$, respectively. Monthly returns are used to generate the descriptive statistics. Therefore, the monthly logarithmic return $R_{i, t}$ is

$$
\mathrm{R}_{\mathrm{i}, \mathrm{t}}=\ln \frac{\mathrm{P}_{\mathrm{i}, \mathrm{t}}}{\mathrm{P}_{\mathrm{i}, \mathrm{t}-1}}
$$

The logarithmic return is calculated using the DDC-MGARCH model to estimate the conditional volatility and correlations. As the non-stationary macro-economic variables may entail a spurious regression, a differential treatment will be applied.

$$
\mathrm{D}_{\mathrm{i}, \mathrm{t}}=\mathrm{X}_{\mathrm{i}, \mathrm{t}}-\mathrm{X}_{\mathrm{i}, \mathrm{t}-1}
$$

where $X_{i, t}$ and $X_{i, t-1}$ denote the economic factor $i$ at times $t$ and $t-1$, respectively. $D_{i, t}$ is the difference of the time series that will be used to study the effect of the economic determinants on volatility and correlations. With the above alteration, the sample ranges from Feb. 1987 to Feb. 2014 with 325 observations for each time series.

\section{Empirical Results}

REIT Performance. REITs are commonly considered financial products offering a competitive long-term performance record, portfolio benefits and inflation protection. The data retrieved above are used to analyze stocks, private real estate and the two types of REITs. As Figure 1 indicates, the indexes increase in the long run. They appear to be related in most areas, yet the performance of these indexes demands further investigation.

Kernel density estimation is a non-parametric means of estimating the probability density function of a random variable. It is closely related to a histogram but can be accorded properties such as smoothness or continuity through the selection of a suitable kernel. In this paper, the Epanechnikov kernel is employed in the Kernel density approximation and the bandwidth is the smoothing parameter. As Figure 2 indicates, the CSXR density is highly centralized, while the others are not. They share the common feature of a fat left tail, which may indicate asymmetry.
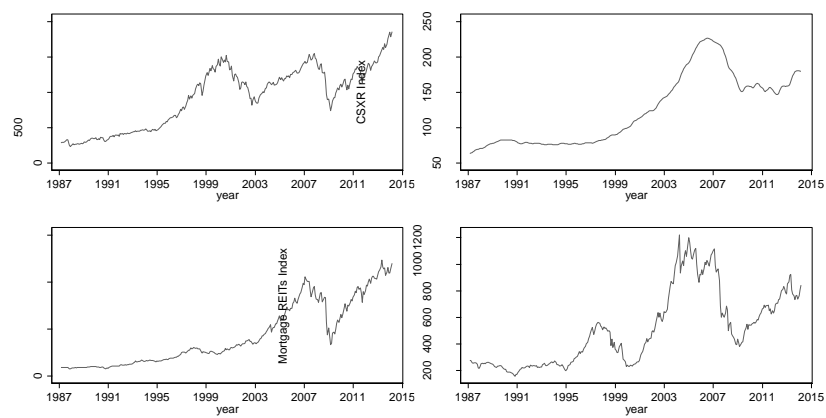

Figure 1. S\&P 500, CSXR, Equity and Mortgage REIT price indexes. CSXR is an unsecuritized real estate price index.
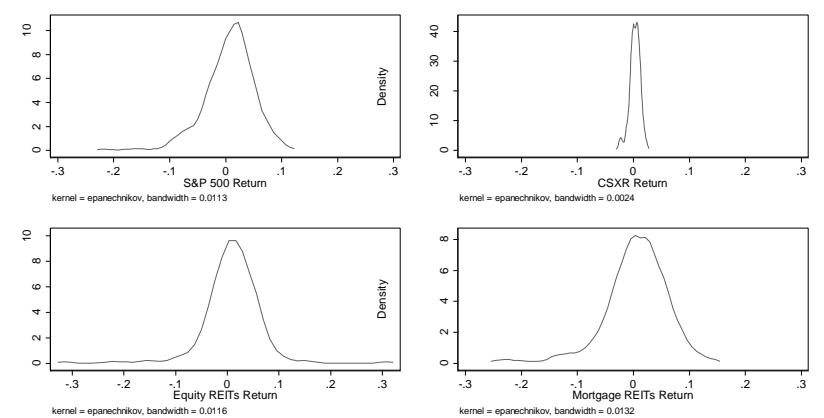

Figure 2. Kernel density plots of S\&P 500, CSXR,

Equity and Mortgage REITs. CSXR is an unsecuritized real estate price index.

Therefore, we calculate summary statistics for the S\&P 500, CSXR, Equity REITs, Mortgage REITs and Risk-free Interest Rate in Panel A of Table 1. The summary statistics include the mean, median, standard deviation, minimum, maximum, skewness and kurtosis. Equity REITs have the largest average monthly return, while the return on private real estate is the smallest of the four assets. Compared to the means, the medians of the S\&P 500, Equity and Mortgage REITs are relatively similar. The most important explanation for the differences is that the S\&P 500 and Mortgage REITs 
exhibit greater left-skewness than Equity REITs. The standard deviation of Equity REITs is the largest, while that of the private sector is the smallest.

The Sharpe Ratio is commonly employed to examine the performance of an investment by adjusting its risk. The ratio measures the excess return (or risk premium) per unit of excess risk. Following the definition of the Sharpe Ratio, we obtain the following formula:

$$
S_{p}=\frac{E\left[R_{a}-R_{b}\right]}{\sigma\left[R_{a}-R_{b}\right]}
$$

where $R_{a}$ is the asset's return, $R_{b}$ is the benchmark return on the risk-free interest rate, and $\sigma$ is the standard deviation of this excess return. There are two approaches to applying the Sharpe Ratio. Let $R_{b}=0$; then we have $S_{P 1}$, and let $R_{b}=$ the risk-free interest rate, yielding $S_{P 2}$. Panel A of Table 1 reports the Sharpe Ratios, both $S_{P 1}$ and $S_{P 2}$, of the four assets. A higher Sharpe Ratio indicates a better return at the same level of risk. With $S_{P 1}$, CSXR $>$ EREIT $>\mathrm{S} \& P 500>M R E I T$, where $>$ denotes "is preferred to"; with $S_{P 2}$, EREIT $>$ S\&P500 $>C S X R>M R E I T$. The substantial difference between these results resulted from the different treatment of the risk-free interest rate. We prefer $S_{P 2}$, as it considers the Risk-free Interest Rate, which represents the opportunity cost of money. The analysis demonstrates that REITs are competitive long-term investment products.

The correlations are reported in Panel B of Table 1. All S\&P 500 firms are listed, as are most Equity and Mortgage REITs. The two exhibit some correlation, which is likely due to the impact of the macro-environment and market sentiment. However, a common topic of investigation is their dynamic relationship. Conditional volatility and correlation are present in most multivariate time series. Whether dynamic relationship exists and what affects it will be discussed in the following sections.

Table 1. Descriptive statistics of four assets and the risk-free interest rate

\begin{tabular}{|c|c|c|c|c|c|}
\hline & S\&P500 & CSXR & EREIT & MREIT & Risk-free \\
\hline \multicolumn{6}{|c|}{ Panel A: Descriptive Statistics } \\
\hline Mean & 0.0069 & 0.0033 & 0.0095 & 0.0052 & 0.0029 \\
\hline Median & 0.0115 & 0.0041 & 0.0117 & 0.0103 & 0.0032 \\
\hline Std. Dev. & 0.0439 & 0.0093 & 0.0534 & 0.0568 & 0.0020 \\
\hline Minimum & -0.2176 & -0.0279 & -0.3167 & -0.2411 & 0.0000 \\
\hline Maximum & 0.1116 & 0.0262 & 0.3102 & 0.1417 & 0.0071 \\
\hline Skewness & -0.9113 & -0.5503 & -0.7956 & -1.0753 & -0.0560 \\
\hline Kurtosis & 5.5655 & 3.7424 & 11.7646 & 5.9619 & 1.9053 \\
\hline Sharpe 1 & 0.1569 & 0.3524 & 0.1786 & 0.0917 & - \\
\hline Sharpe2 & 0.0913 & 0.0428 & 0.1243 & 0.0408 & - \\
\hline \multicolumn{6}{|c|}{ Panel B: Correlation Matrix } \\
\hline S\&P500 & 1 & & & & \\
\hline CSXR & 0.0340 & 1 & & & \\
\hline EREIT & 0.5658 & 0.0977 & 1 & & \\
\hline MREIT & 0.3828 & 0.0579 & 0.4847 & 1 & \\
\hline Risk-free & 0.0304 & 0.0475 & -0.0523 & -0.0986 & 1 \\
\hline
\end{tabular}

Notes: 1. EREIT and MREIT represent Equity REIT and Mortgage REITs, respectively. CSXR is an unsecuritized real estate price index.

2. Sharpe1 is zero benchmark Sharpe Ratio $S_{P 1}$, and Sharpe2 is risk-free interest rate benchmark Sharpe Ratio $S_{P 2}$.

Dynamic Volatility and Correlations. A DCC-MGARCH model can be estimated by applying the Two-Stage method to the monthly data on the S\&P 500, CSXR, Equity and Mortgage REITs. The covariance matrix $\mathrm{H}_{\mathrm{t}}$ contains the conditional variance and covariance for each period considered. Figure 3 depicts the dynamic conditional volatility series, which are diagonal elements of $\mathrm{H}_{\mathrm{t}}$. During the period 2007-2008, the U.S. subprime mortgage crisis triggered the financial crisis, which is considered the worst financial crisis since the Great Depression of the 1930s, and resulted in the threat of the total collapse of large financial institutions, bank bailouts by national governments, and downturns in stock markets worldwide. In many areas, the housing market also suffered, resulting in evictions, foreclosures and prolonged unemployment. In most panels of Figure 3, the largest volatility 
cluster can be observed during the financial crisis. The indexes declined rapidly during this period. Moreover, apart from the crisis of 2007-2008, variance clusters appear during crisis periods: the market crash of 1987, the First Gulf War in 1990-1991, the Asian financial crisis of 1998, the dot-com bubble in 2000, 9-11 in 2002, the Second Gulf War in 2003, and the sovereign debt crisis of 2012. The variance between indexes rose dramatically. This increased the risk levels of various portfolio in the market. To reduce risk, investors should adjust their portfolios, reducing total holdings and increasing the shares assigned to low-risk assets. If the shift in variance does not receive sufficient attention, the traditional strategy would tend to recommend holding additional assets, the value of which seems to be underestimated, ultimately leading to greater investment losses.

The conditional correlation matrix $\boldsymbol{R}_{t}$ can be calculated from $\boldsymbol{H}_{t}$. Figure 4 plots the conditional correlations between CSXR and the S\&P 500, Equity and the S\&P 500, Mortgage and the S\&P 500, Equity and the CSXR, Mortgage and the CSXR, and Mortgage and Equity. Overall, the correlations between Equity and the S\&P 500, Mortgage and the S\&P 500 and Mortgage and Equity are high, yet the other three are low. Each correlation exhibits volatility, which appears random but has similar periodic trends. For example, deterioration of the economic situation and intensive rescue measures, in 2007-2008, lead to the market volatility, the increasing correlations, and significant fat left tail of daily logarithmic returns (Yan, 2013[13]). The impact of the financial crisis on the conditional variance and conditional correlation coefficients demonstrated the effect that macroeconomic risk has on the portfolio, and the portfolio should be adjusted and optimized in a timely manner and accordance with changes in the economic environment.
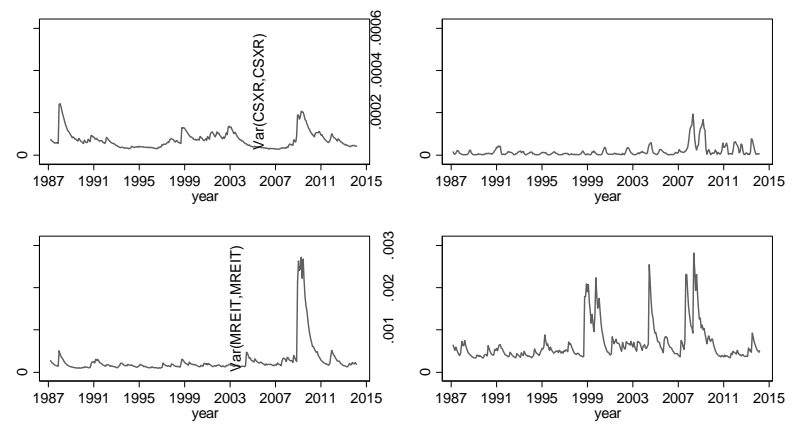

Figure 3. Dynamic conditional volatility series for assets. EREIT and MREIT represent Equity REIT and Mortgage REITs, and CSXR is an unsecuritized real estate price index.
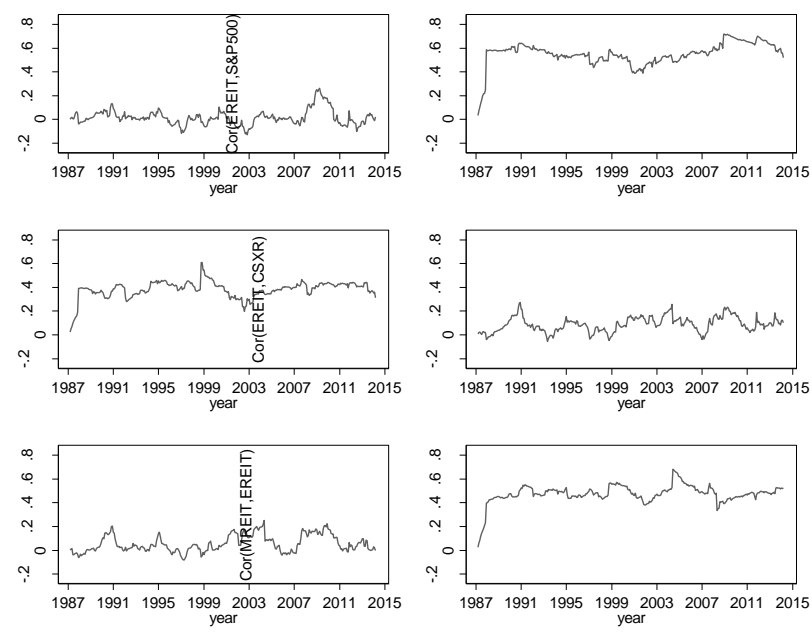

Figure 4. Dynamic conditional correlations for pairwise assets. EREIT and MREIT represent Equity REIT and Mortgage REITs, and CSXR is an unsecuritized real estate price index.

Economic Determinants of Volatility and Correlations. To determine whether economic fluctuations contribute to the changes in the correlations, Fei et al. (2010[10]) develop regression models for each time series as follows:

$$
\operatorname{Corr}_{\mathrm{i}, \mathrm{t}}=\alpha_{\mathrm{i}} \operatorname{Corr}_{\mathrm{i}, \mathrm{t}-1}+\beta_{0, \mathrm{i}} \mathrm{M}_{\mathrm{t}}+\beta_{1, \mathrm{i}} \mathrm{M}_{\mathrm{t}-1}+\mathrm{d}_{\mathrm{t}}+\varepsilon_{\mathrm{i}, \mathrm{t}}
$$

where $\operatorname{Corr}_{i, t}$ denotes the conditional correlation of the $i$-th model at time $t, \alpha_{i}$ is the auto-regression parameter, $\beta_{0, i}$ and $\beta_{1, i}$ are the vector parameters for the current and lagged macroeconomic variable vectors $\boldsymbol{M}_{t}$ and $\boldsymbol{M}_{t-1}, \boldsymbol{d}_{t}$ indexes the month dummy variables to control for seasonal effects, and $\varepsilon_{i, t}$ is a random term.

In this study, we employ an additional auto-regression model. The terms $Y_{i, t}$ represent the four variances and six correlations to be modeled. Stationary tests indicate that all of the $Y_{i, t}$ are stationary but all macroeconomic variables are nonstationary. Fortunately, the tests reveal that the first-order differentials of the economic variables are stationary. Therefore, let the differential macroeconomic variable vector $\boldsymbol{D}_{t}\left(\boldsymbol{D}_{t}=\boldsymbol{M}_{t}-\boldsymbol{M}_{t-1}\right)$ be the explanatory variable. Generally, seasonal effects need to be considered. We also introduce month dummy variables into every model and perform an F-test on 
these dummy variables. However, none of the tests are significant, even at the $10 \%$ level. Consequently, our AR(1) model is the following:

$$
Y_{i, t}=\alpha_{i} Y_{i, t-1}+\beta_{i} D_{t}+\varepsilon_{i, t}
$$

where $\alpha_{i}$ and $\beta_{i}$ are the parameters, $Y_{i, t}$ is the conditional volatility or correlation of the $i$-th model at time $t$, and $\boldsymbol{D}_{t}$ is a differential macroeconomic variable vector.

Not all of the differential macroeconomic variables have a significant influence on $Y_{i, t}$ significantly. We thus employ the Sequential Elimination of Regressors (SER) approach to filter related factors until we obtain a pure model. Using Eq. (6) and the SER approach, we obtain the regressions of variances presented in Table 2. The coefficient on the lagged term in each model is close to 1 . We apply a hypothesis test to these coefficients:

$$
\mathrm{H}_{0} \text { : the coefficient on the lagged term is equal to } 1
$$

If the $\mathrm{P}$-value $<0.05$ and the coefficient is less than 1 , the $\mathrm{AR}(1)$ model is a stationary process. This indicates that the impact of macroeconomic variables is persistent but not permanent. However, if this is not the case, $\operatorname{AR}(1)$ is nonstationary, meaning that the impact might be persistent and permanent.

In the model (Eq. 6), we applied five macroeconomic instrumental variables to determine their effects. The unemployment rate affects short-term economic conditions. Rising unemployment will represent the short-term (1 year in this study) economic downturn. Changes in the term spread reflect investors' expectations of long-term (10 years in this study) economic conditions. A rise in the term spreads, indicates future economic recovery. The credit spread responds to the economic conditions in credit markets. As the economy declines, the credit spread widens, credit risk rises, and liquidity is reduced. Changes in the inflation rate have different effects on stocks and real estate. When the pace of inflation accelerates, a credit crunch is expected and stocks are bearish, but anti-inflationary assets, namely real estate and its derivatives, are bullish. The interest rate is an important mechanism employed by the central bank for macroeconomic regulation. The risk-free interest rate rises as monetary policy is tightened, meaning that liquidity declines. This is often the case when an economy is overheating and inflation is severe.

\begin{tabular}{|c|c|c|c|c|}
\hline & $\begin{array}{l}\text { Variance of } \\
\text { S\&P } 500\end{array}$ & CSXR & EREIT & MREIT \\
\hline Lagged term & $0.9946 * * *$ & $0.9091 * * *$ & $1.0026 * * *$ & $0.9343 * * *$ \\
\hline \multicolumn{5}{|l|}{ Differential of $\left(\times 10^{-4}\right)$ : } \\
\hline unemployment rate & --- & --- & --- & --- \\
\hline term spread & --- & --- & --- & --- \\
\hline credit spread & $1.5539 * * *$ & $0.3422 * * *$ & $5.3403 * * *$ & --- \\
\hline inflation rate & $0.1275^{*}$ & --- & $-1.2078 * * *$ & $0.5100 * *$ \\
\hline risk-free interest rate & $0.7631 * * *$ & $-0.1218 * * *$ & $-1.1671 *$ & $-1.2612 *$ \\
\hline$R^{2}$ & 0.9729 & 0.8708 & 0.9393 & 0.9190 \\
\hline $\mathrm{H}_{0}: \mathrm{lag}=1, \mathrm{P}$-value & 0.6143 & 0.0000 & 0.8617 & 0.0005 \\
\hline
\end{tabular}

Table 2. Regression of variances on lagged terms and differential macroeconomic variables

Notes: 1. EREIT and MREIT represent Equity REIT and Mortgage REITs, respectively, and CSXR is an unsecuritized real estate price index.

2. Significance at the $10 \%, 5 \%$ and $1 \%$ levels is denoted by $*, * *$ and $* * *$, respectively.

3. --- denotes that the variable is eliminated during the SER process.

In Table 2, the variances are affected by the credit spread, inflation rate and risk-free interest rate. An increase in the credit spread typically indicates a depression and decreased investor confidence. The coefficients of the credit spreads $(1.5539,0.3422,5.3403$ in Table 2) indicate an economic downturn and increased credit risk. Stocks, Equity REITs, and real estate entities are affected. Their volatility tends to increase. The income from Mortgage REITs derives from real estate companies, rather than real estate itself, entailing less risk and a more certain income. Therefore, it can approximate changes in the credit markets. Accelerated inflation is expected to result in monetary policy tightening, which is employed to reduce liquidity. This policy contracts the monetary market, and hence the volatility of stocks and mortgage REITs $(0.1275,0.5100)$ increases. Moreover, it 
stabilizes the economy and revenues from rental property, thereby reducing the volatility of Equity REITs (-1.2078). An increase in the risk-free interest rate, which implies tighter monetary policy, occurs when the economy is overheated. This leads to fluctuations in financial markets $(0.7631)$ and the stability of the real economy. Thus the volatility of direct real estate and related products will decline $(-0.1218,-1.1671,-1.2612)$. The unemployment rate and term spread are highly important macroeconomic variables but seem to have no effects on volatility. The unemployment rate is an exogenous variable that affects short-term economic conditions, yet it does not directly affect the liquidity of the money market or the status of the real estate market. Term spreads reflect expected long-term economic conditions. They have little impact on asset prices and volatility in the short term. The models indicate that CSXR and MREIT are stationary process, and their impacts are persistent in the long term.

In Table 2, we study the pairwise correlation between assets. The $R^{2}$ of all models appear acceptable well. Only three of them, CSXR and S\&P 500, EREIT and CSXR and MREIT and CSXR, are stationary. A reduction in the term spread $(-2.5525,-2.3890)$ entails increased short-term borrowing costs and a liquidity shortage. Under these conditions, economic risks may increase, and hence this is also the case for certain portfolio risks, as the correlations between EREIT and S\&P500 and MREIT and S\&P500 increase. The credit spread more directly affects the real economy than it does the financial system. An increase in the credit spread first affects the private sector and then stock and Equity REITs $(2.7192,3.6002)$. The correlation between Mortgage REITs and CSXR is insignificant, as Mortgage REITs derive their revenues from interest instead of from rent. The inflation rate affects the model estimates of the correlation between MREIT and EREIT at the 10\% significance level (0.4103). An increase in the inflation rate may increase the risk of portfolios containing Equity and Mortgage REITs. A depressed economy follows a decline in the risk-free interest rate (-3.2904, -2.2581), and the correlations between EREIT and the S\&P 500 and MREIT and the S\&P 500 increase portfolio risk.

Ultimately, Equity REITs are high-risk, high-yield assets. Analytical results using the adjusted Sharpe Ratio indicate that investors prefer Equity REITs to stocks, direct real estate, and equity and mortgage REITs. Apart from the 2007-2008 crisis, the variance between Equity REITs and other assets is quite low. There is a dynamic change in the correlation between Equity REITs and other indices. Intuitively, an economic downturn generally entails a trend toward increased correlation. The relationships between the economic determinants and conditional variables are mixed. The term spread, credit spread, inflation rate and risk-free interest rate play a significant role in determining volatility and correlations.

\section{Conclusion}

REITs play an important role in investment portfolios in the United States. Markowitz, the famous American economist, proposed portfolio theory in 1952, which holds that asset correlations are constant. In reality, investors gradually realize that these correlations are time-varying but regular. We can dynamically optimize an investment portfolio and effectively reduce the overall risk by mastering this law. CITIC Securities Co., Ltd. issued the first REIT in China in May 2014, representing a significant step for China's capital markets. As Chinese investors gain experience with them, REITs will soon become feasible channels to reduce portfolio risk.

When a REIT is added to a portfolio, three key factors, namely, return, volatility and correlation, should receive serious consideration. Among stocks, direct real estate and the two types of REITs, Equity REITs are relatively high-risk and high-yield assets, and the Sharpe Ratio indicates that REITs have the best performance. This study also finds that macroeconomic variables have a significant impact on the conditional volatility and correlation of assets. This effect persists in the long term, as the AR(1) model is nonstationary. When conditional variance and correlations are considered in portfolio decisions, trading signals can be changed to reduce losses during periods of systemic market risk.

Our study differs from prior works in the following ways: (1) we calculate the Sharpe Ratio differently, thereby obtaining different results. (2) Theory predicts asymmetry, but the literature 
reveals that a significant asymmetric effect cannot be detected using monthly data. Therefore, we employ a DDC-MGARCH model instead of AG-DDC-MGARCH in this study. (3) Accounting for the non-stationary variables, we develop a finite difference model that does not include uninformative seasonal dummy variables. (4) Using more recent data, the impact of the 2007-2008 financial crisis on the time series can be clearly observed.

\section{References}

[1] Silvennoinen, A. and T. Ter A Svirta, Multivariate GARCH models, in Handbook of Financial Time Series. 2009, Springer. p. 201-229.

[2] Bollerslev, T., R.F. Engle and J.M. Wooldridge, A capital asset pricing model with time-varying covariances. The Journal of Political Economy, 1988: p. 116-131.

[3] Engle, R., Dynamic conditional correlation: A simple class of multivariate generalized autoregressive conditional heteroskedasticity models. Journal of Business I\& Economic Statistics, 2002. 20(3): p. 339-350.

[4] Cappiello, L., R.F. Engle and K. Sheppard, Asymmetric dynamics in the correlations of global equity and bond returns. Journal of Financial econometrics, 2006. 4(4): p. 537-572.

[5] Devaney, M. and W. Weber, Efficiency, scale economies, and the risk/return performance of real estate investment trusts. JOURNAL OF REAL ESTATE FINANCE AND ECONOMICS, 2005. 31(3): p. 301-317.

[6] Sharpe, W.F., The Sharpe Ratio. 1994. p. 49-58.

[7] Jirasakuldech, B., R.D. Campbell and R. Emekter, Conditional Volatility of Equity Real Estate Investment Trust Returns: A Pre- and Post-1993 Comparison. JOURNAL OF REAL ESTATE FINANCE AND ECONOMICS, 2009. 38(2): p. 137-154.

[8] Wu, M.C., Y.S. Liau and Y.C. Wang, Are REITs defensive? Evidence from the US. AFRICAN JOURNAL OF BUSINESS MANAGEMENT, 2010. 4(7): p. 1386-1389.

[9] Fei, P., L. Ding and Y. Deng, Correlation and volatility dynamics in REIT returns: performance and portfolio considerations. The Journal of Portfolio Management, 2010. 36(2): p. 113-125.

[10] Yang, J., Y.G. Zhou and W.K. Leung, Asymmetric Correlation and Volatility Dynamics among Stock, Bond, and Securitized Real Estate Markets. JOURNAL OF REAL ESTATE FINANCE AND ECONOMICS, 2012. 45(2): p. 491-521.

[11]Erol, I. and A. Ileri, What Determines REIT Returns in Turkey? An Application of Time-Varying Arbitrage Pricing Model in an Emerging REIT Market. IKTISAT ISLETME VE FINANS, 2013. 28(331): p. 9-31.

[12] Guo, W.J. and J. Cai, Portfolio Optimization with Uncertain Exit Time in Infinite-Time Horizon. ACTA MATHEMATICAE APPLICATAE SINICA-ENGLISH SERIES, 2013. 29(4): p. 673-684.

[13] Yan, Y., et al., Financial risks of global main stock indexes before and after financial crisis: An empirical study based on t-distribution. SYSTEMS ENGINEERING - THEORY \& PRACTICE, 2011. 31(5): p. 841-847. 